\title{
Literature Review on the Benefits of Thermotherapy to Boost Immune System and Reduce Viral Replication
}

\section{George Grant* and Jay P Vanden Heuvel}

academyofwellness.com, Canada

*Corresponding Author: George Grant, academyofwellness.com, Canada.
Received: April 28, 2020

Published: May 28, 2020

(C) All rights are reserved by George Grant

and Jay P Vanden Heuvel.

\begin{abstract}
Thermotherapy can profoundly support the immune system to reduce viral replication. The objective of this literature review is to find supportive evidence in scientific literature to validate our previously published work on Thermotherapy using Infrared and negative ions Amethyst Bio mat on Diabetes, Cancer, Sleep Problems and Pain Management [100].
\end{abstract}

Keywords: Thermotherapy; Immune System; Viral Replication

\section{Introduction}

Heat, crystals, gems, flower essences, homeopathy, are just some examples of integrated therapies in the pursuit of optimum health. Gemstones as example, influence specific organs in the physical body. They are of a crystalline structure which can focus on biomolecular level pathways [7]. This can help integrate the life force into the body. Noted to even amplify consciousness (it is also interesting to note that all cells have consciousness). These gems can exert powerful effects upon the meridians, chakras, and subtle bodies of our multi-dimensional body. Another example is color which is not new to the twenty first century. Applied in ancient times was the healing temples of light and color at Heliopolis in Egypt. Afterall, we all need and feel healed from the Sun through resonant infrared energy [100].

Crystals are a growing knowledge that help transmute and transform electromagnetic energy. We have crystals in our cell phones, right? A Ruby crystal was a key component in the very first laser developed by Bell laboratory scientists in the '60's. Liquid crystals (think cell phones/computers) is another example. Biologists have now discovered that even cellular membranes and some structures within the human body are liquid crystals as well. Electromagnetism has potential healing properties. All starting with crystals and gems originating naturally within the Earth. Could this thermotherapy be the next big medical advance? [100].

Amethyst is an example, which is a form of quartz, which has a variety of the color violet. Due to traces of manganese and others. Considered directly connected to the lifeforce of all living things.
A part of the ultraviolet spectrum. It has a lot of history anecdotal evidence associated with it such as improved blood flow. Crystals have been compared to magnets and associated fields.

Thermotherapy is the application of heat. Thermotherapy consists of application of heat for the purpose of changing the cutaneous, intra-articular and core temperature of soft tissue with the intention of improving the symptoms of certain conditions. Another healing agent long known. Uses of thermotherapy is to increase local temperatures of various body parts. Which in turn can turn up the entire body's temperature itself. Or you may know it as a hot bath, far infrared ray (6 - 12 microns), or even in ages past where doctors used drug-induced fever treatments [100].

By increasing the temperature of the skin/soft tissue, the blood flow increases by vasodilation. Any improvement in blood flow helps everything including a healthy microbiome. Even some undesirable viruses are even known to succumb to heat.

The metabolic rate and the tissue extensibility will also increase. Heat increases oxygen uptake and accelerates tissue healing, it also increases the activity of destructive enzymes, such as collagenase, and increases the catabolic rate [99].

The effect of heat on pain is mediated by heat sensitive calcium channels. These channels respond to heat by increasing intracellular calcium. This generates action potentials that increases stimulation of sensory nerves and causes the feeling of heat in the brain. These channels are part of a family of receptors called TRPV receptors (think endocannabinoid system) [98]. 
TRPV1 and TRPV2 channels are sensitive to noxious heat, while TRPV4 channels are sensitive to normal physiological heat. Their receptors allow a number of factors to activate these channels. Once activated, they can also inhibit the activity of purine pain receptors. These receptors, called P2X2 and P2Y2 receptors, are mediated pain receptors and are a part of the peripheral small nerve endings. In peripheral pain, heat can directly inhibit pain. However, when pain is originating from deep tissue, heat stimulates peripheral pain receptors which can alter what has been named "gating" in the spinal cord and reduce deep pain [9].

Previous studies have suggested that temperature can affect the exchange between $\mathrm{Ca}^{2+}$ and $\mathrm{Na}^{+}$in neural cells [9].

Currently, medical devices such as a Bio Mat (certified by the FDA) combine this thermal therapy with negative ions, and gems/ crystals such as Amethyst and Tourmaline [8]. Which works with the body's own natural immunity. Safe and effective.

Our immune system and all functions operate best when our temperature is 36 degrees centigrade. It has been noted a one-degree drop can lower immune function by up to $40 \%$ [8]. This type of therapy has been known to induce heat shock proteins (HSP). HSP is known to protect cells from temperature stress and activate lymphocytes (and other immune cells), this is why mild fevers are beneficial. Far infrared rays ( $8-12 \mathrm{um}$ ) is also used here which the body favors, by inhibiting outside electromagnetic waves. Even known to help rid the body of toxins [86].

What's this all got to do with the microbiome and virus?

Modern medicine has always been focused on biochemistry with good results. But it needs integration. Biophysics or Quantum Biology. Which has excellent merit [86].

Through the use of thermo therapy and crystals it is about helping the body achieve optimum regulation.

In the case of the intestinal lining (the home of the microbiome), it is interwoven with epithelial cells creating the intestinal mucosa. The gut microbiota is dependent upon healthy epithelial cells creating this lining. If the mucosa is damaged from any factor such as diet, toxins, radiation, etc. alterations will exist to the composition of the gut microbes. In other words, their home is being destroyed. Their metabolic waste products they produce may end up leaking into the blood stream versus being eliminated out the intestinal canal [94].

So, thermotherapy can help target cells to regenerate in a healthy way. This in turn can help create a healthier intestinal environment for the community to flourish in optimum balance in a safer environment. Unhealthy tissues contribute to more dysbiosis resulting in disease [10].

In the case of virus, and it depends on which one, it can become inactive or destroyed by heat. In a virus it can contain DNA and RNA which can be denatured. This in turn can make it impossible for the virus particle to bind to a host site. Making it impossible for the virus to penetrate the host's cell membranes or attach to receptor sites. The whole purpose of prevention is to help the virus not bind to a host cell in the first place [88].

\section{The numerous benefits of thermotherapy}

\section{Benefits for the body}

- Promotes improved physical health

- Encourages better sleep

- Stimulates the immune system

- Deeply cleanses the body by eliminating toxins

- Cleans, tones, and tightens the skin and gives it elasticity and firmness

- Improves blood circulation

- Encourages improved nutrient absorption and digestion

- Slows body ageing

* Please note that temperature variations on the body may not be recommended for all. See your medical doctor if you doubt the benefits of thermotherapy on your body and/or medical condition.

\section{Benefits for psychological and emotional health}

- Promotes improved mental health

- Encourages relaxation and eliminates fatigue

- Reduces accumulated stress and tension

- Improves memory and mental alertness

- Creates peace of mind

\section{Benefits for athletes}

- Improves athletic performance

- Soothes muscle aches and pains

- Improves breathing (slower and deeper)

- Aids body remineralization

\section{Table}

The microbiome immune

It has been estimated that the total bacteria on planet Earth are around 5 Nonillion. That is the number 5 followed by 30 zeros. Of those less than $1 \%$ are pathogenic. We live in a bacterial world.

Did you know there are more bacteria just in your gut, than stars in the milky way? 100 trillion bacteria versus 400 million stars. Yet a million bacteria could dance on the head of a pin. Viruses are even smaller. 
Yes, we live in, and are helped kept alive by this bacterial world. We are now more educated than ever on the microbiome (bacteria community inside and on us) of those bacteria. They out number our body's total cell count by $10^{-1}$. And how about viruses? According to the Journal of Virology on September 6, 2013 [1], there are $100,939,140$ viruses if we include 1,740,330 known species of vertebrates, plants, lichens, etc. Hence, we as humans, have inside of us not only a microbiome but a "Virome". And according to Live Science "Everyday more than 800 million viruses are deposited per square meter above the planetary layer. This also does not take into account any new zoonotic viruses" [2].

We also know, the vast majority of viruses will go on to infect all bacteria fore mentioned. In the Journal of Inside Science, January 14, 2020 [3], it was estimated that just swimming in the ocean and ingesting a mouthful of sea water, you would take in 200 million viruses and 20 million bacteria. So how do our bodies continually deal with this onslaught? By way of our immune system.

The microbiome, and even now the virome, acts as a signaling hub. Giving us information in congruency with our individual immunity, genetics, and epigenetics, Factors such as lifestyle, hygiene, and nutrition. If this system is disrupted, these signals lead to Dysbiosis. Dysbiosis is known to develop into diseases. When it comes to optimal health, bacteria (probiotics) and viruses' matter. According to Dr. Vanessa Sperandio, professor of microbiology at the University of Texas Southwestern Medical Center, she presented findings that "signaling systems can be decoded to better understand the three-way conversation between pathogens, microbiota and the host" [4]. That's good news as science catches up to what nature is already doing for us, in us, every day as humans by way of our immune system.

You can compare the microbiome of a person with an anomaly, like irritable bowel syndrome, with that of a dying coral reef as an example. Care of this system is critical to optimum health.

One part of our immune system is known as 'innate'. The innate immune system uses cells called macrophages. They can encode (epi-genetic) memory of past pathogens. They will pass that onto daughter cells. Very helpful in long term immunity. If a new attack surfaces, that has by passed our first line of defense called Adaptive, the innate cells produce extra cytokines that trigger inflammation. Sometimes it can result in a cytokine storm [16,91].

As mentioned, many factors influence our proper immune function including therapies being discussed such as Thermo-therapy and morphogenetic fields. Time for understanding of vibrational medicine, color therapy, and more importantly - the findings of Thermotherapy $[99,100]$.
Before getting into thermotherapy and its benefits, a few things to consider. It has been estimated that there are more than 5 billion cell phones in the world and 4 million microwave towers [5]. This is a concentration of non-ionizing radiation which continues to grow. Now we have the new $5 \mathrm{G}$. Our immune systems are in desperate need of therapies that can help counteract all the man-made radiation, not to mention, pesticides, herbicides, chemicals, toxic metals, medical isotopes, etc. No one knows what the synergy of all this in combination, is even doing to our immune systems day to day. It is not out of context to say, our immune health IS health [16].

In the Journal of Science 1/21/2011 it was stated "practical concept to fixing peoples metabolism is an impaired microbiome. Food, supplements, fiber, probiotics, faith, family, fitness, fun and improving frequency is the key" [49].

According to the CDC June 13, 2016, traumatic brain injuries have increased over past decade. A leading cause of disability worldwide. This is important to know because the gut and the brain are intricately linked by way of the gut-brain axis. Communication between the microbiome and the brain. One affects the other. So even invisible enemies are coming at us through this discourse, and even not just physical trauma, but frequencies are as well $[16,68,91]$.

Recent research suggests something called senescent cells, which are cells that have stopped dividing but are not actually dead. They secrete small proteins (cytokines) that can damage cells around them even further. It was once believed that senecents help stave off malignancy. Still known they help with wound healing because the cytokines they secrete help activate the immune system. But if too many and out of balance, it is believed they contribute to low level inflammation, aging, and can increase cancer. The older we get the more senescent cells we have. Radiation is known to increase these types of cells mixed amongst our healthy cells. Medicine is trying to find a way to rid us of too many [6]. But how do you kill that which isn't really alive? What if we could prevent this from even happening in the first place or help the body help itself by correcting the imbalance? $[16,68,91]$.

Improving frequency has not gotten the attention it deserves. Especially when you consider it is frequencies that can disrupt our immunity (innate) too as mentioned [71].

An increase in serotonin and heat shock protein production results from thermotherapy treatment on a Bio Mat along with the addition of the Bio Belt being applied to the abdominal area $[10,22,40,46,100]$. 
Research shows that serotonin, a neurotransmitter that exists in the brain also exists in the intestines; it is also well known that $90 \%$ of the serotonin exists in the small intestine. As such, our intestine uses the neurotransmitter serotonin to balance the active immune functions of our body [83].

There are over 500 different types and 100 trillion bacilli living inside our intestines. Among these, there exist beneficial bacteria such as Bifidus and Lactobacillus and also harmful bacteria such as clostridium perfringens, bacillus and staphylococcus. Our level of immunity increases, while the increase of harmful bacteria leads to the decrease of immunity level [89].

By warming the abdominal region with smooth far-infrared radiation, the beneficial bacteria will become more active, producing heat shock protein and increasing our level of immunity.

The Bio Mat is a natural heating pad which lies on top of a massage table or your home mattress. It converts electricity through a computerized control panel, produced by Texas Instruments, into Far Infrared Rays (FIR), nature's invisible light. FIR was discovered by NASA to be the safest, most beneficial light wave. This reduces pain, swelling, increases blood flow and reduce stress by increasing the secretion on serotonin [100].

The Bio Mat also produces Negative Ions, nature's energizer, which deliver a molecular level massage. This accelerates and deepens all healing and cleansing processes. It balances $\mathrm{pH}$ by decreasing acidity and is considered the "Master Power Switch" which activates the body's entire cellular communication system, making everybody function work better! Negative Ions alleviate allergies, migraines and sinus problems [100].

These two components are transferred through Amethyst Quartz channels which cover the entire Bio Mat's surface. Amethyst Quartz is natures Super Conductor, scientifically found to offer the steadiest, most powerful delivery of healthy far infrared light waves and the highest vibrational frequencies into the body [100].

The core of Bio Mat technology is a combination of far infrared rays [6-12 microns], negative ion effects and the conductive properties of amethyst channels. These three powerful health stimulators are combined in a single, easy-to-use product with remarkable healing properties. The Bio Mat manufactured and distributed by Richway International Inc. delivers soothing, deep-penetrating heat while stimulating the regeneration of damaged cells in the body. This highly effective therapy is now available to medical professionals and home consumers who want to improve health and well-being with products based on Nobel prize-winning scientific research pioneered by NASA and developed using pure, natural materials.
The Bio-Mat Professional is registered an FDA Medical Device \#2954299 [Grant, George, Evaluating Thermotherapy using the Amethyst Bio Mat] [100].

The effect of thermotherapy on preventing viral replication:

The basic process of viral infection and virus replication occurs in these ways:

- Adsorption - virus (capsid) binds to the host cell.

- Penetration - virus injects its genetic material (genome DNA/RNA) into a host cell.

- Viral Genome Replication - virus genetic material replicates using the host's cellular machinery.

- Assembly - viral components and enzymes are produced and begin to assemble.

- Maturation - viral components assemble and new copies $(10,000)$ of viruses fully develop.

- Release - newly produced viruses are expelled from the host cell.

- Viruses may infect any type of cell including animal cells, plant cells, and bacterial cells.

\section{It's about frequency}

Royal Raymond Rife used an invention of his own to help identify spectroscopic signatures of microbes and viruses. He used a slit spectroscope attached to a standard microscope. Then he slowly rotated a quartz prism focusing light of a single wavelength onto a virus he was looking at.

It is a known fact that every molecule oscillates at its own distinct frequency. He selected a wavelength that resonated with the signature frequency of a virus. We know atoms come together to form a molecule and are held together in a configuration with a covalent energy bond. This bond emits and absorbs its own specific electromagnetic frequency. No two molecules have the same signature or frequency. By using this technology, Rife helped make the invisible (virus) visible.

He could now observe a virus actively invade a healthy cell. This is called "heterodyning". Illuminating a virus with two different wavelengths of the same ultraviolet frequency. This resonated with the signature of the virus. The two wavelengths produced interference when they merged like waves on an ocean. This interference produced a third visible wave in the electromagnetic spectrum. Again, making the virus visible. This is not done with today's electron microscopes. 
Rife used the same principles he discovered to denature viruses by resonance. Increasing the resonance, or intensity, the virus basically exploded. Also, he found it did not damage the healthy cell. Because the healthy cell resonated at a different frequency. This is quantum physics using quantum energy. Rife died in 1971 and in his life was deemed a "quack". Too bad because modern medicine is full of frequency today.

This helps us understand why gems, crystals, and thermotherapy show huge promise. Interference by using this same concept of resonance and frequency. By use of magnetic and electrical frequencies. Resulting in disruption of the pathogen. Another analogy is death of a pathogen by nano-electrocution.

In the case of negative ions. Molecules carry either positive or negative electrons. When there is an extra negative electron, we call this a negative ion. Positively charged ions (extra positive charge) do not really have a positive effect. Especially on our physical and mental health. Negatively charged ions DO have a positive effect. They elevate our mood by increasing serotonin levels, they help stabilize blood pressure, increase the body's alkalinity, strengthen bones, heighten immunity, accelerate physical recovery, they purify and clean the air and more.

Negatively charged ions are abundant in nature with the highest concentrations forming near moving water and old growth forests. Have you ever noticed how you feel when you sit near a waterfall or walk along the beach? You breathe in that fresh, clean air and you feel energized yet calm, alive, vibrant, refreshed.

Positive ions come mostly from electromagnetic fields, plastics, pollution, etc. They also can contribute to poor cell performance, low immunity, a poor microbiome and make us more susceptible to pathogens.

Exposure to many positive ions (like indoors too long) along with prolonged and undealt stress (physical, emotional, mental) increases a cells vulnerability (natural immunity). Even a cell phone (EMF) or microwaves can alter a cells cytoplasm and alter its frequency. Constantly wearing down the cells defense. Every negative emotion, pathogen or disease state has its own frequency and can alter cellular defense. The value of thermotherapy using heat, negative ions and crystals is making more sense now.

A virus pathogen can introduce an associated harmonic frequency of its own which becomes disharmonic to the once healthy cell. Rife went on to find viruses could be destroyed by the use of electromagnetic frequency (11). All biophysics today (MRI) uses magnetism and energy.
Scientifically we know the majority of most pathogens resonate at a frequency of about 890-910 terahertz. Similar to germicidal ultraviolet lights used in hospitals. Helping the body with harmonious frequency is basically a supplement. An integrated therapy to anything you are doing to help with your own optimum health.

Thermotherapy, negative ions, and crystals incorporate the best of this research.

The role of the immune system in eradicating malignant cells is not yet clarified, however spontaneous regression of some cancers has been demonstrated to be associated to the induction of fever and activation of immunity [1-3]. The crucial importance of fever in these regressions justifies the attempt to induce artificial thermal elevation of body temperature (hyperthermia) or Thermotherapy for mimicking natural fever effects on cancer and boost immune system [100].

Heat shock proteins (HSPs), their role in antigen presentation and in cancer immunity

When cells are submitted to a variety of stressful events (e.g., heat, hypoxia, glucose deprivation), there is a rapid and coordinated increase in the expression of a group of proteins, the so-called heat shock proteins (HSPs) [1].

HSPs are one of the most conserved groups of proteins throughout evolution and are classified into several families according to their molecular weight in kilodaltons (e.g., HSPs 100, 90, 70, s60, s40) and their compartmentalization inside the cell (cytosol or endoplasmatic reticulum, mitochondria) [22,38-40]. HSPs fulfil different important intracellular processes, such as protein synthesis, folding and they are activated by a specific set of genes induced by different physical stress such as elevated temperature, hypoxia, glucose deprivation and oxidative reagents [39]. Linearly at molecular level, heat stress increases the synthesis of HSP 70 until a certain threshold temperature that varies according to cell type. Beyond this threshold temperature their synthesis is inhibited and an exponential cell death follows $[41,42]$.

Initially, the role of HSPs, peculiarly of HSP70, appeared to be implicated in the thermotolerance [41]. Recently, they have been recognized to activate the immune system becoming a specialized carriers of antigenic peptides in vivo as well [43,44]. In fact, Srivastava., et al. [44] have established that HSPs are not immunogenic per se, but when they are complexed with antigenic peptides, become powerful immunogens. In fact it has been found that cancer derived HSPs are highly specific and this specificity is associated with the agglomerate HSP/ peptide. Once HSP-complexes (MCH1/MCH2+HSPs) are exposed at the outer surface of cancer 
cells, they interact with macrophages and dendritic cells through specific surface receptors $[40,45]$. HSP70 binds to the surface of monocytes through the Cluster of Differentiation (CD)14 (CD14) receptor, whereas gp96 binds with the $\alpha-2$ macroglobulin/LDL receptor related protein or CD91. Furthermore, HSP60 has been demonstrated to be a ligand for the Toll-like receptors 4 (TLR4 and TLR2) complex on macrophages $[40,46]$. These data support the data that APCs (macrophages, dendritic cells) have evolved receptors for detecting danger signals (HSPs complexes) released during neoplasia.

The exposure of the HSP chaperoned peptides by the MCH1 and $\mathrm{MCH} 2$ molecules to macrophages or dendritic cells triggers a secretion of inflammatory cytokines and costimulatory molecules, such as: IL-6,IL-12; TNF- $\alpha$, B7 that induce the maturation of DCs towards the $\mathrm{T}_{\mathrm{H}} 1$ phenotype $[47,48]$. Their association, with a broad array of peptides generated within cells, make HSPs a good candidate for cancer vaccines [49]. In fact HSP-peptide complexes, isolated from a patient's tumor, can be utilized as tailored patient specific antigens, which would avoid the search for specific epitopes. HSPs, isolated from cancer cells but not those derived from normal cells, can generate an immune response, as observed by Tamura and Srivastava $[50,51]$. The potentiality of HSPs in tumor eradication has been validated in more than ten types of tumor models of different histologies and in different animal species, demonstrating that: (a) microgram quantities of HSPs are sufficient to generate substantial immune response $[40,45]$; (b) the immunogenicity of antigens expressed by dying cells occurs via necrosis or apoptosis. Among the two dying mechanisms only necrotic cells or heat stressed cells have been demonstrated to be able to elicit a tumorspecific immunity [52,53]. Several non-randomised clinical trials with heat shock protein-peptide complexes on human cancers are actually in progress $[22,86]$.

Active and passive nonspecific immunotherapy (Cytokines, IL2, INF-; $\alpha$, GM-CSF)

IL-2 has been the first cytokine used alone or in combination with LAK cells for the treatment of different types of metastatic cancers. Patients with metastatic renal cell carcinoma and melanoma receiving IL-2+LAK had a higher rate of complete response. IL-2 has been administered with different regimes and doses demonstrating an elevated toxicity [12-14].

Numerous other cytokines have been identified and tried clinically, however only Interferon- $\alpha$ (INF- $\alpha$ ) and Granulocyte Macrophage Colony Stimulating Factor (GM-CSF) are currently used given the high toxicity of Interferon- $\gamma$ and IL-12 [8,12,14].
Active specific immunotherapy (Vaccine, gene therapy, heat shock proteins)

Serological identification of antigens by recombinant expression cloning technique (SEREX) has recently permitted to detect more than 1500 TAAs holding a specific antitumor activity $[52,56]$.

Tumour vaccination (TV) is a therapeutic form of therapy involving patients with detectable disease and it is used for triggering a robust, appropriate and specific immune response towards a well characterized TAAs, avoiding immune-tolerance and providing a long lasting immune response [52,57]. The first tumor vaccines were obtained by irradiating tumor cells. The obtained results were not enthusiastic, inducing several authors to combine tumor vaccines with nonspecific immune modulators, such as BCG, New Castle Disease virus (NDV) and Detox; however, the survival rate was comparable to the group treated with chemotherapy. To ameliorate the results, newer vaccines, including allogenic or autologous tumor cells, were genetically manipulated in order to produce a stronger immune response. Tumor cells, were encoded with different cytokines, however only those engineered to produce GMCSF proved to induce tumor rejection [58].

\section{Conclusion}

A large number of clinical trials, involving different strategies, are actually being conducted and have been reviewed elsewhere. Some of them will however be discussed for a positive interaction with Thermotherapy [hyperthermia treatment] and Immune System as well as viral replication $[6,87,92,100]$.

\section{Bibliography}

1. Papac RJ. "Spontaneous regression of cancer". Cancer Treatment Reviews 22 (1996): 395-423.

2. Abel U. "Spontanremissionen und fieberhafte Erkrantungen". In: Heim ME, Schwarz R, eds. "Spontanremissionen in der Onkologie" (1998): 68-75.

3. Hobohm U. "Fever and cancer". Cancer Immunology, Immunotherapy 50 (2001): 391-396.

4. Bickels J. “Coley toxin: Historical perspective". IMAJ 4 (2002): 471-472.

5. Coley-Nauts H and McLaren J. "Coley toxins-the first century. "Consensus On Hyperthermia for 1990s". Advances in Experimental Medicine and Biology 267 (1990): 483-500.

6. Dickson JA and Shah SA. "Immunologic aspects of hyperthermia". In: Storm FK, edition. "Hyperthermia in cancer therapy". Boston, MS: G K Hall Publisher (1983): 487-543. 
7. Dickson JA and Shah SA. "Hyperthermia and the immune response in cancer therapy". Cancer Immunology, Immunotherapy 9 (1980): 1-10.

8. Dranoff G. "Cytokines in cancer pathogenesis and cancer therapy”. Nature Reviews Cancer. 4 (2004): 11-22.

9. Diefenbach A and Raulet DH. "The innate immune response to tumors and $1^{\text {st }}$ role in the induction of T-cell immunity". Nature Reviews Immunology 188 (2002): 9-21.

10. Hilf N., et al. "The heat shock protein Gp96 links innate and specific immunity". International Journal of Hyperthermia 18 (2002): 521-533.

11. Palucka K., et al. "Dendritic cells and tumour immunity". Current Opinion in Oncology Endocrinology Metabolism Investigational Drugs 1 (1999): 282-290.

12. Bremes AJA and Parmiani G. "Immunology and immunotherapy of human cancer: Present concepts and clinical developments". Critical Reviews in Oncology/Hematology 34 (2000): $1-25$.

13. Ben-Efraim S. "One hundred years of cancer immunotherapy: A critical appraisal”. Tumor Biology 20 (1999): 1-24.

14. Davis ID., et al. "Rational approaches to human cancer immunotherapy". Journal of Leukocyte Biology 73 (2003): 3-29.

15. Schirrmacher V., et al. "T-cell priming in bone marrow: The potential for long-lasting protective anti-tumor immunity". Trends in Molecular Medicine 9 (2003): 526-534.

16. Lord EM and Frelinger JC. "Tumor immunotherapy: Cytokines and antigen presentation". Cancer Immunology, Immunotherapy 46 (1998): 75-81.

17. Shurin MR., et al. "TH1/TH2 in cancer, transplantation and pregnancy". Springer Seminars in Immunopathology 21 (1999): 339-359.

18. Nishimura T., et al. "Distinct role of antigen specific T Helper type 1 (Th1) and Th2 cells in tumor eradication In vivo". Journal of Experimental Medicine 190 (1999): 617-627.

19. Titu LV., et al. "The role of CD8+ T cells in immune responses to colorectal cancer". Cancer Immunology, Immunotherapy 51 (2002): 235-247.

20. Carlos TM. "Leukocyte recruitment at sites of tumour: Dissonant orchestration". Journal of Leukocyte Biology 70 (2001): 171-184.
21. Fauriat C., et al. "Natural Killer Cell-Triggering receptors in patients with acute leukaemia”. Leukemia Lymphoma 44 (2003): 1683-1689.

22. Hoos A and Levey DL. "Vaccination with heat shock proteinpeptide complexes: From basic science to clinical applications". Expert Review of Vaccines 2 (2003): 369-379.

23. O' ByrneKJ., et al. "The relationship between angiogenesis and the immune response in carcinogenesis and progression of malignant disease". European Journal of Cancer 36 (2000): 151-169.

24. Vaupel P., et al. "Blood flow, oxygen and nutrients supply, and metabolic microenvironment of human tumors, a review". Cancer Research 49 (1989): 6449-6465.

25. Folkman J. "Tumour angiogenesis: Therapeutic implications". The New England Journal of Medicine 285 (1971): 1182-1186.

26. Freitas I and Baronzio GF. "Tumour hypoxia, reoxygenation and oxygenation strategies: Possible role in photodynamic therapy". The Journal of Photochemistry and Photobiology B: Biology 11 (1991): 3-30.

27. Berges $\mathrm{G}$ and Benjamin L. "Tumorigenesis and the angiogenic switch". Nature Reviews Cancer 3 (2002): 401-410.

28. Griffioen AW and Molena G. "Angiogenesis: Potentials for pharmacological intervention in the treatment of cancer, cardiovascular diseases, and chronic inflammation". Pharmacological Reviews 52 (2000): 238-268.

29. Griffioen AW., et al. "Angiogenesis modulates the tumour immune response". International Journal of Experimental Pathology 79 (1998): 363-368.

30. Papetti M and Herman I. "Mechanisms of normal and tumourderived angiogenesis". The American Journal of Physiology: Cell Physiology 282 (2002): c947-c970.

31. Alexandroff AB., et al. "Sticky and smelly issues: Lessons on tumour cell and leukocyte trafficking, gene and immunotherapy of cancer". British Journal of Cancer 77 (1998): 1806-1811.

32. Carlos TM and Harlan JM. "Leukocyte-endothelial adhesion molecules". Blood 84 (1994): 2068.

33. Kitayama J., et al. "Suppressive effect of basic fibroblast growth factor on trans endothelial emigration of CD4(+) T-lymphocyte". Cancer Research 54 (1994): 4729. 
34. Barleon B., et al. "Migration of human monocytes in response to Vascular endothelial growth factor (VEGF) is mediated via the VEGF receptor flt-1". Blood 87 (1996): 3336-3343.

35. Borgstrom PG., et al. "Leukocyte adhesion in angiogenic blood vessels". Journal of Clinical Investigation 99 (1997): 22462253.

36. Griffioen AW., et al. "Endothelial ICAM-1 expression is suppressed in human malignancies; role of angiogenic factors". Cancer Research 56 (1996): 1111.

37. Mantovani A., et al. "Macrophage polarization: Tumor associated macrophages as a paradigm for polarized M2 mononuclear phagocytes". Trends in Immunology 23 (2002): 549-555.

38. Hightower LE. "Heat shock, stress proteins, chaperones and proteotoxicity”. Cell 66 (1991): 191-197.

39. Smith DF., et al. "Molecular chaperones: Biology and prospects for pharmacological intervention". Pharmacological Reviews 50 (1998): 494-513.

40. Manjili MH., et al. "Immunotherapy of cancer using Heat shock proteins". Frontiers Bioscience 7 (2002): d43-d52.

41. Li GC., et al. "Heat shock proteins, thermotolerance and their relevance to clinical hyperthermia". International Journal of Hyperthermia 11 (1995): 459-488.

42. Fortin A., et al. "Overexpression of the 27 KDA heat shock protein is associated with thermotolerance and chemoresistance but not with radioresistance". Journal International Journal of Radiation Oncology Biology Physics 46 (2000): 1259-1266.

43. Wallin RPA., et al. "Heat shock proteins as activators of the innate immune system". Trends in Immunology 23 (2002): 130135.

44. Przepiorka D and Srivastava PK. "Heat shock protein-peptide complexes as immunotherapy for human cancer". Molecular Medicine Today 4.11 (1998): 478-484.

45. Manjili MH., et al. "Cancer immunotherapy: Stress proteins and hyperthermia". International Journal of Hyperthermia 18 (2002): 506-520.

46. Wells A and MalKovsky M. "Heat shock proteins, tumor immunogenicity and antigen presentation: An integrated view". Immunology Today 21 (2001): 129-132.

47. Milani Y., et al. "Heat shock protein 70 in antigen presentation and immune stimulation". International Journal of Hyperthermia 18 (2002): 563-575.
48. Flohe SB., et al. "Human heat shock protein 60 induces maturation of dendritic cells versus a TH1-promoting phenotype". Journal of Immunology 170 (2003): 2340-2348.

49. Liu B., et al. "Overcoming immune tolerance to cancer by heat shock protein vaccines". Molecular Cancer Therapeutics 1 (2002): 1147-1151.

50. Tamura Y., et al. "Immunotherapy of tumors with autologous tumor - derived heat shock protein preparations". Science 269 (1995): 117-120.

51. Srivastava P. "Purification of heat shock protein-peptide complexes for use in vaccination against cancers and intracellular pathogens". Methods 12 (1997): 165-171.

52. Basu S., et al. "Necrotic not apoptotic cell death release heat shock proteins, which deliver a partial maturation signal to dendritic cells and activate the NF-kB pathway". International Immunology 12 (2000): 1539-1546.

53. Feng H., et al. "Stressed apoptotic tumor cells express heat shock proteins and elicit tumor specific immunity". Blood 197 (2001): 3505-3512.

54. "Horizons in Cancer Therapeutics". From Bench to Bedsides (2001).

55. Rosenberg SA. "Progress in the development of immunotherapy for the treatment of patients with cancer". Journal of Internal Medicine 250 (2001): 462-475.

56. Sahin U., et al. "Serological identification of human tumor antigens". Current Opinion in Immunology 9 (1997): 709-716.

57. Bitton RJ., et al. "Cancer Vaccines: An update with special focuses on gangliosides antigens (Review) ". Oncology Reports 9 (2002): 267-276.

58. Ockert D., et al. "Advances in cancer immunity". Immunology Today 20 (1999): 63-65.

59. Espinoza-Delgado I "Cancer vaccine". The Oncologist 7.3 (2002): s20-s33

60. Ribas A., et al. "Current development in cancer vaccines and cellular immunotherapy". Journal of Clinical Oncology 21 (2003): 2415-2432.

61. Osanto S. "Vaccine trials for the clinician: Prospects for tumor antigens". The Oncologist 2 (1997): 284-299.

62. Parmiani G., et al. "Vaccination of patients with solid tumours". Annals of Oncology 14 (2003): 817-824 
63. Fernandez NC., et al. "Dendritic cells directly trigger NK cell functions: Cross-talk relevant in innate antitumor immune response". Nature Medicine 5 (1999): 405-411.

64. Celluzzi CM., et al. "Peptide pulsed dendritic Cells induce antigen - specific CTL-mediated protective antitumor activity". Journal of Experimental Medicine 183 (1996): 283-287.

65. Ribas A., et al. "Cancer immunotherapy using gene- modified dendritic cells". Current Gene Therapy 2 (2002): 57-78.

66. Weber J and Fong L. "Clinical trials of Dendritic Cells in cancer In: Lotze M, Thomson AW, eds.“Dendritic Cells”San Diego, San Francisco: Academic Press (2001): 561-571.

67. Haupt K., et al. "The potential of DNA vaccination against tumour-associated antigens for antitumor therapy". Bulletin of Experimental Biology and Medicine 227 (2002): 227-237.

68. Pawelec G., et al. "Cells and Cytokines in immunotherapy and gene therapy of cancer". Critical Reviews in Oncogenesis 10 (1999): 83-127.

69. Baar J. "Clinical applications of dendritic cell cancer vaccines". The Oncologist 4 (1999): 140-144.

70. Gabrilovich DI., et al. "Production of vascular endothelial factor by tumour inhibits the functional maturation of dendritic cells". Nature Medicine 2 (1996): 1096-1103.

71. Yamaguchi Y., et al. "Contrasting effects of TGF- $\beta 1$ and TNF- $\alpha$ on the development og dendritic cells from progenitors in mouse bone marrow". Stem Cells 15 (1997): 144-153.

72. Sharma S., et al. "Tumor cycloxygenase 2 -dependent suppression of dendritic cell function". Clin Cancer Res. 9 (2003): 961968.

73. Romano G. "Gene transfer in experimental medecine". Drugs and Therapy Perspectives 16 (2003): 267-276.

74. Peng K-W. "Strategies for targeting therapeutic gene delivery". Molecular Medicine Today 5 (1999): 448-453.

75. Romano G., et al. "Gene transfer technology in therapy. Current applications and future goals". Stem Cells 17 (1999): 191-202.

76. Navarro JG., et al. "Gene therapy of cancer". European Journal of Cancer 35 (1999): 867-885.

77. Kufe DW., et al. "Principles of gene therapy". In: Bast, Kufe, Pollock, Weichselbaum, Holland, Frei, eds. "Cancer Medicine". Hamilton, Ontario: BC Decker Publisher (2000): 876-890.
78. Rochlitz CF. "Gene therapy of cancer". Swiss Medical Weekly 131 (2001): 4-9.

79. Farzaneh F., et al. "Gene therapy of cancer". Immunology Today 19 (1998): 294-296.

80. Clark RP and Hersh EM. "Cationic lipid-mediated gene transfer: Current concepts". Current Opinion in Molecular Therapeutics 1 (1999): 158-76.

81. Davis ME. "Non -viral gene delivery systems". Current Opinion in Biotechnology 13 (2002): 128-131.

82. Maurer N., et al. "Development in liposomal drug delivery systems". Expert Opinion on Biological Therapy 1 (2001): 923-947.

83. Boulikas T. "Liposome DNA delivery and uptake by cells". Oncology Reports 3 (1996): 989-005.

84. Koshkina NV., et al. "Biodistribution and pharmacokinetics of aerosol and intravenously administered DNA-polyethyleneimine complexes: Optimisation of pulmonary delivery and retention". Molecular Therapy 8 (2003): 249-254.

85. Densmore CL. "The reemergence of aerosol gene delivery: A viable approach to lung cancer therapy". Current Cancer Drug Targets 3 (2003): 273-284.

86. Singh-Jasuja H., et al. "The heat shock protein gp96: A receptor-targeted cross-priming carrier and activator of dendritic cells". Cell Stress Chaperones 5.5 (2000): 462-470.

87. Mazzaferro V., et al. "Vaccination with autologous derived Heat shock protein gp96 after liver resection for metastatic colorectal cancer". Clinical Cancer Research 9 (2003): 3235-3245.

88. Saper $\mathrm{CB}$ and Breder $\mathrm{CD}$. "The neurologic basis of fever". The New England Journal of Medicine 30 (1994): 1880-1886.

89. Dinarello CA. "Cytokines as endogenous pyrogens". The Journal of Infectious Diseases 179.2 (1999): s294-s304.

90. Netea MG and Kulberg BJ. "Circulating cytokines as mediators of fever". The Journal of Infectious Diseases 179.2 (1999): s178s184.

91. Blatteis CM and Sehic E. "Cytokines and fever". Annals of the New York Academy of Sciences 840 (1998): 608-618.

92. Ahlers 0., et al. "Induced hyperthermia causes significant changes in lymphocytes". Critical Care 2.1 (1998): 002.

93. Jampel HD., et al. "Fever and immuneregulation". Journal of Experimental Medicine 157 (1983): 1229-1238. 
94. Hanson DF. "Fever, temperature, and the immune response". Annals of the New York Academy of Sciences 813 (1997): 453464.

95. Bell JF and Moore GF. "Effects of high ambient temperature on various stage of rabies virus infection in mice". Infection and Immunity 10 (1974): 510-515.

96. Hasday JD. "The influence of temperature on host defenses". In: Mackowiak PA, edition. "Fever: Basic mechanisms and management". $2^{\text {nd }}$ edition Philadelphia: Lippincott-Raven Publishers (1977): 177-196.

97. Roberts NJ. "Impact of temperature elevation on immunologic defences”. RID 13 (1991): 452-472.

98. Lederman HM., et al. "Interleukin-1 driven secretion of interleukin-2 is highly temperature dependent". Journal of Immunology 138 (1987): 3808-3811.

99. Gautherie M. "Hyperthermia and the immune system". In: Gautherie M, edition. "Whole Body Hyperthermia: Biological and clinical aspects". Berlin-Heidelberg-New York: SpringerVerlag 19926-19915.

100. Grant George F. "Evaluating Thermotherapy using The Amethyst Bio belt and the Infra Red Negative Ions Amethyst Bio Mat in 12 subjects to reduce fat, pain and stress over 3 months". International Journal of Aesthetic and Anti-Ageing Medicine (2013).

\section{Assets from publication with us}

- Prompt Acknowledgement after receiving the article

- Thorough Double blinded peer review

- Rapid Publication

- Issue of Publication Certificate

- High visibility of your Published work

Website: www.actascientific.com/

Submit Article: www.actascientific.com/submission.php

Email us: editor@actascientific.com

Contact us: +919182824667 